\section{A possible link between the pseudoexfoliation syndrome and coronary artery disease}

M Citirik¹, G Acaroglu1 , C Batman ${ }^{1}$, L Yildiran² and O Zilelioglu ${ }^{1}$

\section{Abstract}

Purpose This is a collaborative case-control study from Ophthalmology and Cardiology departments of a tertiary care hospital, designed to explore the relationship between coronary artery disease (CAD) and pseudoexfoliation syndrome (PEX).

Method In all, 50 patients with CAD proven by coronary angiography, and 50 controls with normal coronary angiographic findings were compared in terms of PEX, other vascular diseases, and retinal vascular findings. $\chi^{2}$-test and Student's $t$-test were used for statistical analysis. Results The number of patients with PEX among CAD $(+)$ patients was substantially larger than controls. In all, 28 of 50 CAD $(+)$ patients and only 12 of 50 CAD (-) patients had PEX. PEX was significantly associated with CAD $(P=0.001)$. When all patients were regrouped according to the presence of PEX, patients with PEX did not differ from patients without PEX in terms of age $(P=0.360)$ and sex $(P=0.507)$, but the prevalence of CAD was higher $(P=0.001)$ and fundoscopic findings of vascular diseases were significantly more prominent $(P=0.0001)$ in PEX $(+)$ patients. Discussion We demonstrated statistically significant difference in the prevalence of PEX in CAD patients, and also in the prevalence of CAD in PEX $(+)$ individuals. These were striking differences. We should consider the possibility of the presence of PEX in CAD patients; and the predisposition of PEX $(+)$ persons for CAD, which necessitates a fundus examination for findings of systemic vascular diseases. Eye (2007) 21, 11-15. doi:10.1038/sj.eye.6702177; published online 24 March 2006

Keywords: pseudoexfoliation syndrome; coronary artery disease; angiography

\section{Introduction}

Pseudoexfoliation syndrome (PEX) is characterized with progressive accumulation of an abnormal extracellular fibrillar material in anterior structures of the eye and extraocular tissues including skin and connective tissue portions of various visceral organs. ${ }^{1}$ PEX is usually seen among older patients. ${ }^{2}$

Pseudoexfoliation material consists of a central fibrillar component embedded in an amorphous ground substance. ${ }^{3}$ The fibrillar portion has been characterized as amyloid, laminin, oxytalan, and various elastic tissue and basement membrane components. ${ }^{4}$ The available histochemical data suggest a complex glycoprotein-proteoglycan structure containing both noncollagenous basement membrane components and epitopes of the elastic fibre system. ${ }^{5,6}$

Mitchell et $a l^{7}$ investigated the relation of pseudoexfoliation to systemic vascular history. They found the history of either angina or hypertension was significantly associated with presence of PEX. The purpose of this study was to determine possible relationships between coronary artery disease (CAD) and PEX.

\section{Materials and methods}

The study was carried out from January 1999 to December 2003 by SSK Ankara Eye Hospital and SSK Ankara Hospital Department of Cardiology. A total of 50 randomly selected Anatolians of Turkish descent patients who were referred to the coronary unit and found to have ischaemic heart disease by angiography were enrolled in the study group (CAD $(+))$. At the same time period an age and sex matched control group was consisted of patients
'SB Ankara Eye Hospital, Turkey

${ }^{2}$ SB Ankara Diskapi Hospital, Department Of Cardiology, Turkey

Correspondence: M Citirik, SB Ankara Ulucanlar, Fakülteler Mah. Yazgan Sk. NO: 34/12 Cebeci/Ankara/ Turkey

Tel: + 90312362 3222;

Fax: + 903123124827 .

E-mail:mcitirik@

hotmail.com

Received: 13 April 2005 Accepted in revised form: 29 September 2005 Published online: 24 March 2006 
with normal coronary angiograms (CAD (-)). Coronary angiography performed to these patients due to coronary symptoms. Cardiac team was blind to the patients' conditions.

Diagnosis of PEX was made on observing the characteristic greyish particulate matter on the anterior lens capsule after pupillary dilatation; by slit lamp examination. Complete ophthalmological examination included visual acuity, applanation tonometry, and dilated examination of the posterior segment. A patient questionnaire was also filled in for each patient recording personal history of diabetes mellitus (DM) and hypertension (HT). We investigated patients' personal histories of diabetes mellitus and hypertension, because these two systemic vascular diseases are the most prevalent in this age group. Since our patients were being evaluated by coronary artery disease; we presumed they had a history of angina and/or previous coronary arterial problems.

To determine the statistical significance of the observed differences in the prevalence of PEX in the two groups,

$\chi^{2}$ test was used. Statistical significance was accepted as $P<0.05$.

The overall group of 100 patients were regrouped according to the presence of PEX and compared in terms of systemic and retinal vascular disease. Differences between mean age and sex were also assessed (Student's $t$-test and $\chi^{2}$ test).

\section{Results}

Characteristics of the original study group of CAD patients and the age-sex matched control group of CAD patients are shown in Table 1. Presence of PEX was more often encountered in CAD patients. In all, 28 of 50 CAD (+) patients $(56.0 \%)$ and only 12 of 50 CAD (-) patients $(24.0 \%)$ had PEX. This difference reached statistical significance $(P=0.001)$. Both DM and HT (especially HT) were more prevalent in the study group, also were fundoscopic vascular changes; but these differences did not reach to statistical significance.

Characteristics of PEX $(+)$ patients are shown in Table 2. In overall, 100 patients with a mean age of 58.74 \pm 14.70 , 40 had PEX, and 60 did not. PEX (+) patients did not seem to be significantly older; neither the female/male ratio was any different in the two groups.

In all, 11 of pseudoexfoliative patients had glaucoma $(27,5 \%)$ and six of these patients had CAD $(+)(15 \%)$. In all, 18 of pseudoexfoliative patients had cataract (45\%). On the other hand, one of PEX (-) patients had glaucoma $(1,6 \%)$ and these patients had no CAD $(+)$. Six of PEX (-) patients had cataract $(10 \%)$.

CAD was present in 28 of 40 patients with PEX (70.0\%) and 22 of 60 patients without PEX (36.6\%). This difference reached to statistical significance $(P=0.001)$. Fundoscopic vascular changes were significantly more frequent in the PEX $(+)$ group $(P=0.001)$. DM and HT did not show any significant difference among these groups. We did not meet with diabetic retinopathy. We used Keith, Wagener, and Barker classification for description vascular changes in the fundus. We found the $70 \%(44 / 63)$ of patients in group I, 30\% (19/63) in group II. We did not meet with group III and IV.

\section{Discussion}

This syndrome is characterized by deposits of white, fluffy material over the anterior chamber structures, including the trabecular meshwork. White dandruff-like material is also seen on this central disc, the zonular fibres, anterior hyaloid membrane, pupillary and anterior iris, trabecula, and infrequently the cornea, and by cycloscopy on the ciliary processes. ${ }^{8}$ Histopathologically, pseudoexfoliative material on all surfaces appears as bush-like eosinophilic excrescences. ${ }^{9}$

Table 1 Characteristics of patients when grouped according to the angiographic results

\begin{tabular}{|c|c|c|c|c|c|}
\hline & \multicolumn{2}{|c|}{$C A D(+)$ patients $\mathrm{n}: 50$} & \multicolumn{2}{|c|}{$C A D(-)$ patients $\mathrm{n}: 50$} & \multirow[t]{2}{*}{ Statistical significance } \\
\hline & Male $\mathrm{n}: 31$ & Female n: 19 & Male $\mathrm{n}: 28$ & Female n: 22 & \\
\hline Mean age (year) & 63.11 & 62.90 & 56.57 & 53.73 & No $(P: 0.360)$ \\
\hline PEX & 15 & 13 & 7 & 5 & Yes $(P: 0.001)$ \\
\hline \multicolumn{6}{|c|}{ Vascular changes in fundus } \\
\hline Group I & 14 & 11 & 11 & 8 & No $(P: 0.147)$ \\
\hline Group II & 6 & 4 & 5 & 4 & No $(P: 0.147)$ \\
\hline Group III and IV & - & - & - & - & - \\
\hline Diabetes mellitus & 9 & 7 & 6 & 4 & No $(P: 0.171)$ \\
\hline Hypertension & 16 & 12 & 12 & 8 & No (P: 0.109) \\
\hline
\end{tabular}

CAD: coronary artery disease, PEX: pseudoexfoliation syndrome. 
Table 2 Characteristics of patients when grouped according to the presence of PEX

\begin{tabular}{|c|c|c|c|}
\hline & PEX $(+)$ patients $\mathrm{n}: 40$ & PEX (-) patients n: 60 & Statistical significance \\
\hline Mean age & $60.57 \pm 13.88$ & $56.92 \pm 15.52$ & No $(P: 0.360)$ \\
\hline Ratio of females & $18 / 22$ & $23 / 37$ & No $(P: 0.507)$ \\
\hline CAD & 28 & 12 & Yes $(P: 0.001)$ \\
\hline Vascular changes in fundus & 34 & 29 & Yes $(P: 0.0001)$ \\
\hline Diabetes mellitus & 11 & 15 & No $(P: 0.780)$ \\
\hline Hypertension & 22 & 26 & No $(P: 0.253)$ \\
\hline Glaucoma & 11 & 1 & Yes $(P: 0.0001)$ \\
\hline Cataract & 18 & 6 & Yes $(P: 0.0001)$ \\
\hline
\end{tabular}

CAD: coronary artery disease, PEX: pseudoexfoliation syndrome.

Although exfoliation eventually tends to affect both eyes, as would be expected of a systemic disorder, up to two third of patients have deposits in one eye only. ${ }^{10}$ Occasionally this unilaterality persists until advanced ages. The condition progressed to bilaterality in $13 \%$ of patients in one long-term study. ${ }^{11}$

The prevalence of PEX syndrome increases markedly with age. ${ }^{12}$ For example, the prevalence of PEX syndrome in the USA was found to be $0.6 \%$ for those in the age range 52-64 years and 5\% in the age range $75-85$ years. ${ }^{13}$ Aasved reported respective prevalence of pseudoexfoliation of $4.0 \%$ in UK, $4.7 \%$ in Germany, and $6.3 \%$ in Norway. ${ }^{14}$ Among Australian aborigines over age 60 , Taylor et al ${ }^{15}$ noted a $16.3 \%$ prevalence of pseudoexfoliative changes. Forsius has personally studied Finns, Lapps, Eskimos in Greenland, Canada and Alaska, Icelanders, populations in Tunis, India and Peru and four populations in the USSR. The prevalences vary from $0 \%$ in Eskimos to $21 \%$ in Finns over 60 years of age, and are at the same high level in Lapps, Finns, Russians in Novosibirsk and Icelanders, but significantly lower in all the others. ${ }^{16}$ In Turkey, Yalaz et al ${ }^{17}$ examined 1356 persons over 40 years of age. They found the frequency of pseudoexfoliation syndrome over 60 years of age, was $11.2 \%$, the percentage of glaucoma in patients with pseudoexfoliation syndrome was $34.3 \%$, the percentage of cataract in persons with pseudoexfoliation syndrome was $88.1 \%$. In our study, we found $24 \%$ the prevalence of PEX in control group. According to us, this high value is related with the link of pseudoexfoliation syndrome and ischaemic disease. Ischaemic disease is one of the commonest diagnoses in Turkey. ${ }^{18}$ The highest correlation between CAD and risk factors was family history of CAD, followed by DM, hyperlipidemia, hypertension, and smoking, in decreasing order. ${ }^{18}$

Kivela et al, ${ }^{19}$ reported that immunoreactivity was more common in older pseudoexfoliative patients than in younger age groups. Since pseudoexfoliation syndrome develops with age, evidence supports the theory that the vasculopathy may represent an early preclinical stage of this syndrome and that it is an integral part of the disease. Kivela et al believed that the vasculopathy is causally related to the development of classic exfoliation deposits. They have shown that vasculopathy is detectable earlier than are frank exfoliation deposits on the cilliary epithelium and lens capsule.

Cataract is seen in about $40 \%$ of affected eyes. ${ }^{11}$ High incidence of phacodonesis, spontaneous lens dislocation, and vitreous complications during cataract extraction caused by a pathologically altered zonular apparatus are known in eyes with PEX syndrome. ${ }^{20}$ Moreover, fibrillin could be immunolocalized on the light microscopic level to PEX material and its precursor at all lenticular sites, supporting the possibility that defects in the zonular elastic microfibrillar system might form the basis for the PEX process. ${ }^{5}$

In all, 40-60\% of cases are associated with open-angle glaucoma (pseudoexfoliation-capsular glaucoma) and pigment dispersion. ${ }^{21}$ The associated glaucoma seems to be a form of secondary open-angle glaucoma due to the accumulation of pseudoexfoliative material and uveal pigment in the outflow pathways. The material may also be synthesized or processed by the trabecular endothelial cells. The exfoliation material appears to be intimately involved with the adventitia of the iris vessels. Electron microscopy has shown deposits of this material on lens capsule, ciliary body, iris, and even conjunctiva, and extensive atrophy of iris pigment epithelium. ${ }^{22}$ Amorphous masses are formed in the optic nerve in pseudoexfoliative glaucomatous atrophy. ${ }^{23}$ Vascular involvement is seen as disc haemorrhages in glaucoma and as newly formed iris capillaries in $\mathrm{PEX}^{24}$ therefore, vascular endothelial engagement might be a primary cause of glaucoma and PEX.

A hereditary basis for pseudoexfoliation has been strongly suspected, although transmission across generations has been documented infrequently. ${ }^{25}$ The disease has been reported in identical twins. Environmental factors have also been considered, especially cumulative exposure to actinic radiation, ${ }^{26}$ as 
well as slow virus infection or other immunologic process. ${ }^{27}$ Janciauskiene $e t a l^{28}$ examined the presence of Alzheimer's disease related proteins, such as Alzheimer's peptide and serine proteinase inhibitor, $\alpha$-1-antichymotrypsin in cataractous PEX $(+)$ eyes. Alzheimer's peptide was found in $38 \%$ of all cases. Li $e a^{29}$ studied the amyloid P protein in pseudoexfoliative fibrillopathy. Amyloid P protein was demonstrated by immunostaining in all 14 samples of ocular and conjunctival PEX material studied. Since the well-known association of amyloid $\mathrm{P}$ protein is with amyloidosis, the present findings raised the possibility that PEX may be a form of amyloidosis.

The strength of HLA association is supportive evidence for a genetic component to the development of pseudoexfoliation of the lens capsule. ${ }^{30}$ There is a genetic predisposition for CAD also. Especially premature atherosclerosis often appears to be familial. In many instances this can be attributed to the inheritance of risk factors, such as hypertension, diabetes mellitus, and hyperlipidemia. Occasionally, families with excessive premature vascular disease can be found in which none of the known risk factors appears to be operating. ${ }^{31}$

Fibrils that resemble those of exfoliation material have been found in electron microscopic examination of several extraocular tissues. ${ }^{32}$ Schlötzer-Schredart found fibrillopathy in visceral organs like heart, liver, and lung. Therefore, he believed and hypothesized that the pseudoexfoliation is a systemic disease. ${ }^{33}$ In 1995 Repo determined $42 \%$ of patients who have had the transient ischaemic attack have also pseudoexfoliation syndrome. ${ }^{34}$ In that study, Color Doppler imaging in the ophthalmic artery blood flow spectra of patients who have had transient ischaemic attack and PEX showed an increasing index of resistance in the ophthalmic artery.

Mitchell $e t a l^{7}$ investigated the relation of pseudoexfoliation to systemic vascular history. They collected detailed medical history from the patients, including a history of diabetes, hypertension, systemic vascular events, and smoking. A history of either angina or hypertension was significantly associated with presence of PEX after multivariate adjustment, including age, sex, glaucoma, and vascular risk factors. According to the detailed medical history, they suggested that pseudoexfoliation might be associated with the development of vascular disease.

In our study, the diagnosis of CAD is angiographically proven. To our knowledge, similar studies in the literature depend on vascular histories of the patients. Although there may be a bias (an angiography is unlikely to be done on patients with no symptoms of CAD), we believe that angiography is now being done almost routinely, and we chose our control patients among those who had symptoms only, with normal ECG's, and who were eventually found to have normal coronary angiograms. Therefore, we believe this study is especially meaningful in this respect.

According to our statistical analysis, CAD patients showed significantly higher prevalence of PEX. We can speculate about a possible connection between the two. Also, we can say that both PEX and fundoscopic vascular changes are most likely to accompany CAD. When we regrouped our total patient group in terms of the presence of PEX, we saw that there were no differences in the mean age and sex distribution. Therefore, we presumed that the old age factor was eliminated.

We used Keith, Wagener, and Barker classification for description vascular changes in the fundus. According to this classification

Group I: minimal narrowing of the retinal arteries,

Group II: narrowing of the retinal arteries in conjunction with regions of focal narrowing and arteriovenous nicking,

Group III: abnormalities seen in groups I and II, as well as retinal haemorrhages, hard exudation, and cottonwool spots,

Group IV: abnormalities encountered in groups I through III, as well as swelling of the optic nerve head.

We found the $70 \%(44 / 63)$ of patients in group I, $30 \%(19 / 63)$ in group II. We did not meet with group III and IV.

As a conclusion, we recommend that no matter what sex and age; PEX $(+)$ persons should be screened for $\mathrm{CAD}$, and CAD patients should be screened for the presence of PEX. Fundoscopic examination is likely to show evidence of a systemic vascular disease in PEX $(+)$ individuals. Further studies with larger populations are needed to confirm this relationship.

\section{References}

1 Streeten BW, Li Z-Y, Wallace RN, Eagle RC, Keshgegian AA. Pseudoexfoliative fibrillopathy in visceral organs of a patient with pseudoexfoliation syndrome. Arch Ophtalmol 1992; 110: 1757-1762.

2 Forsious H. Exfoliation syndrome in various ethnic populations. Acta Ophtalmol Scand 1988; 66(Suppl 184): 71-85.

3 Morrison J, Green W. Light microscopy of the exfoliation syndrome. Acta Ophtalmol (Copenhagen) 1988; 66(Suppl 184): 5-27.

4 Dark A, Streeten B, Cornwall C. Pseudoexfoliative disease of the lens: a study in electron microscopy and histochemistry. Br J Ophtalmol 1977; 61: 462-472.

5 Schöletzer-Schrehardt U, Dörfler S, Naumann GOH. Immunohistochemical localization of basement membrane components in pseudoexfoliation material of the lens capsule. Curr Eye Res 1992; 11: 343-355. 
6 Li Z-Y, Streeten BW, Wallace RN. Association of elastin with pseudoexfoliative material: an immunoelectron microscopic study. Curr Eye Res 1988; 7: 1163-1172.

7 Mitchell P, Wang JJ, Smith W. Association of pseudoexfoliative syndrome with increased vascular risk. Am J Ophtalmol 1997; 124: 684-687.

8 Mizuno K, Murois S. Cycloscopy of pseudoexfoliation. Am J Ophthalmol 1979; 87: 513.

9 Dark AJ, Streeten BW. Pseudoexfoliation syndrome. In: Garner A, Klintworth GK (eds). Pathobiology of Ocular Disease, A Dynamic Approach, Part B, 2nd ed. Marcel Dekker: New York, 1992 pp 1303-\{nd\}1320 (in press).

10 Henry JC, Kruptin T, Schmitt M, Lauffer J, Miller E, Ewing $\mathrm{MQ}$ et al. Long-term follow-up of pseudoexfoliation and the development of elevated intraocular pressure. Ophthalmology 1987; 94: 545-552.

11 Roth M, Epstein DL. Exfoliation syndrome. Am J Ophthalmol 1980; 89: 477.

12 Newell F. The glaucomas. In: Newell F (ed). Ophthalmology. Principles and Concepts. St Louis: Mosby, 1992, pp 380-381.

13 Leibouitz HM, Krueger DE, Maunter LR. The framingham eye study monograph. Surv Ophtalmol 1980; 24(Suppl): 335-610.

14 Aasved H. The geographical distribution of fibrillopathia epitheliocapsularis, so-called senile exfoliation or pseudoexfoliation of the anterior lens capsule. Acta Ophthalmol 1969; 47: 792.

15 Taylor HR, Hollows FC, Mann D. Pseudoexfoliation of the lens in Australian aborigines. Br J Ophthalmol 1977; 61: 473.

16 Forsius $H$. Exfoliation syndrome in various ethnic populations. Acta Ophthalmol Suppl 1988; 184: 71-85.

17 Yalaz M, Othman I, Nas K, Eroglu A, Homurlu D, Cikintas $\mathrm{Z}$ et al. The frequency of pseudoexfoliation syndrome in the eastern Mediterranean area of Turkey. Acta Ophthalmol (Copenh) 1992; 70(2): 209-213.

18 Ekmekci A, Ercan H, Prifti J, Ozkan E. The epidemiology of ischemic heart disease in Turkey. Tip Fak Mecm 1966; 29(1): 100-110.

19 19-Kivela T, Hietanem J, Uusitalo M. Autopsy analysis of clinically unilateral exfoliation syndrome. Invest Ophtalmol $\mathcal{E}$ Vis Sci 1997; 38: 2008-2014.

20 Schöletzer-Schrehardt U, Naumann GOH. A histopathologic study of zonular instability in pseudoexfoliation syndrome. Am J Ophtalmol 1994; 118: 730-743.
21 Ringvold A, Vegge T. Electron microscopy of the trabecular meshwork in eyes with exfoliation syndrome. Virch Arch [Pathol Anat] 1971; 353: 110.

22 Dickson DH, Ramsay MS. Fibrillopathia epitheliocapsularis (pseudoexfoliation): a clinical and electron microscope study. Can J Ophthalmol 1975; 10: 148.

23 Aasved $\mathrm{H}$. The frequency of optic nerve damage and surgical treatment in chronic simple glaucoma and capsular glaucoma. Acta Ophtalmol 1971; 49: 589-600.

24 Vannas A. Flourescein angiography of the vessels of the iris in pseudoexfoliation of the lens capsule, capsular glaucoma and other forms of glaucoma. Acta Ophtalmol 1969; 105: $1-75$.

25 Teikari JM. Genetic factors in simple and capsular open angle glaucoma in population based twin study. Acta Ophthalmol 1987; 65: 715.

26 Taylor HR. The environment and the lens. Br J Ophthalmol 1980; 64: 303.

27 Ringvold A. Exfoliation syndrome: immunological aspects. Acta Ophthalmol Suppl 1988; 184: 66.

28 Janciauskine S, Krakau T. Alzheimer's peptide: a possible link between glaucoma, exfoliation syndrome and Alzheimer's disease. Acta Ophtalmol Scand 2001; 78 328-329.

29 Schlötzer-Schredart U, Koca MR, Neumann GO. Pseudoexfoliation syndrome; ocular manifestation of a systemic disorder. Arch Ophtalmol 1992; 110: 1752-1756.

30 Fitzsman J S, Mulvihill A, Kennedy S, Finch A, Colum LMT, Eustace P. Association of HLA type with pseudoexfoliation of the lens capsule. Br J Ophthalmol 1996; 80: 402-404.

31 Edwin BL. Harrison's Principles of Internal Disease. McGraw-Hill Book Company: New York, 1987; 195: 1022.

32 Amari F, Nagata S, Umihara J, Nohama M, Usuab N, Segowa K. Lectin electron microscopic histochemistry of the pseudoexfoliative material in the skin. Invest Ophtalmol Vis Sci 1994; 35: 3962-3966.

33 Li Y-Z, Streeten BW, Yohai N. Amyloid P Protein in pseudoexfoliative fibrillopathy. Curr Eye Res 1989; 8: 217-227.

34 Repo LP, Suhonen MT, Terasvirta ME, Koivisto KJ. Color Doppler imaging in the ophthalmic artery blood flow spectra of patients who have had a transient ischemic attack; correlations with generalized iris transilluminance and pseudoexfoliation syndrome. Ophthalmology 1995; 102: 1199-1205. 